\section{Hazard analysis and critical control points among Chinese food business operators}

\author{
Stefano Saccares, ${ }^{1}$ Paolo Amadei, ${ }^{2}$ \\ Gianfranco Masotti, ${ }^{2}$ Roberto Condoleo, \\ Alessandra Guidi ${ }^{3}$ \\ ${ }^{1}$ Centro Studi per la Sicurezza \\ Alimentare, Istituto Zooprofilattico \\ Sperimentale delle Regioni Lazio e \\ Toscana, Roma; ${ }^{2}$ Azienda Sanitaria Locale \\ RM/A; ${ }^{3}$ Dipartimento di Scienze \\ Veterinarie, Università degli Studi di Pisa, \\ Italy
}

\section{Abstract}

The purpose of the present paper is to highlight some critical situations emerged during the implementation of long-term projects locally managed by Prevention Services, to control some manufacturing companies in Rome and Prato, Central Italy. In particular, some critical issues on the application of selfcontrol in marketing and catering held by Chinese operators are underlined. The study showed serious flaws in preparing and controlling of manuals for good hygiene practice, participating of the consultants among food business operators (FBOs) to the control of the procedures. Only after regular actions by the Prevention Services, there have been satisfying results. This confirms the need to have qualified and expert partners able to promptly act among FBOs and to give adequate support to authorities in charge in order to guarantee food safety.

\section{Introduction}

Under the influence of some emergencies (mad cow disease, dioxin in feed), there has been a significant development of food laws which led to the enhancement of some normative papers that make up the basis of food security such as the Council Regulation (EC) n. 178 of 28 January 2002 (European Commission, 2002). This last is intended to lay down the general principles and requirements of food law by a series of regulations. More precisely, it has confirmed that food business operators (FB0) are the main responsible for the hygienic and healthy production of food and must adopt the most appropriate measures to ensure consumers' health and expectations by means of the self-control plan following the principles of hazard analysis and critical control points (HACCP).
In the present paper, we want to present some critical comments resulting from the activities carried out by the Prevention Services [National Information System on Agriculture (SIAN) and Veterinary Service] of the Local Health Service of Rome (ASL RM/A), Italy. We compare them with those acquired from a project of integration concerning the European Regulations of the Chinese Community of Prato, carried out by the Territorial Service of the AUSL 4 of Prato (ACSA).

\section{Case Report}

In the period 2007-2009, the Veterinary Service, in cooperation with the Health Food and Nutrition Territorial Service of the AUSL $\mathrm{RM} / \mathrm{A}$, carried out an investigation on the raw fish in Japanese restaurants located in the centre of Rome (Masotti et al., 2010). The primary objective was to evaluate the structural, operational and general hygiene of the equipment and the staff, and to assess the freshness of the fish products used and distributed raw. Thirty restaurants were inspected: most of them were Japanese preparing sushi and sashimi. As for data collection, checklists were arranged individually by the two services, for their investigation, based on the recommendations included in the Guidelines of Latium Region for the implementation of the REG. CE 882/04 (European Commission, 2004). The activity had several positive effects in terms of the awareness of the issues related to the consumption of raw fish preparations and it resulted in a reduction of non-conformities. Still, its most relevant result is the ongoing adoption of the correct procedures for the prevention of Anisakis risk by the FBOs involved. Particularly, the first checks showed a wide use of fresh product not subject to any remediation by freezing. On the contrary, as a result of the prescriptive acts, a greater spread of freezing of the raw material performed on site using correct procedures was detected the following years. As an alternative, the purchase of the product already subject to necessary remediation was registered. Therefore, the project can be considered as a successful example of the interaction between official control and FBOs, especially given that it has been able to act not only on the mere application of regulatory provisions, but also on the cultural approach in preparing of traditional ethnic foods.

In the period 2009-2010, in the province of the AUSL 4 in Prato, a project was launched, aiming at improving the quality level of the retail outlets managed by the Chinese community operators. The project involved all the professionals of the Competent Authority for Food
Correspondence: Stefano Saccares, Centro Studi per la Sicurezza Alimentare, Istituto Zooprofilattico Sperimentale delle Regioni Lazio e Toscana, via Appia Nuova 1411, 00178 Roma, Italy.

Tel/Fax: +39.06 .79099312$

E-mail: stefano.saccares@izslt.it

Key words: FB0, Chinese operator, HACCP.

Conflict of interests: the authors declare no potential conflict of interests.

Received for publication: 13 May 12013. Revision received: 11 July 2014

Accepted for publication: 12 July 2014.

This work is licensed under a Creative Commons Attribution 3.0 License (by-nc 3.0).

(C) Copyright S. Saccares et al., 2014 Licensee PAGEPress, Italy

Italian Journal of Food Safety 2014; 3:1707 doi:10.4081/ijfs.2014.1707

Safety of the AUSL 4 in Prato (ACSA) (Armani et al., 2011; Guidi et al., 2010). The activity involved 24 shops, including 9 supermarkets which sell meat and fish products, 6 supermarkets which sell meat and fish products and other food products, 4 restaurants, 2 stores, 1 street vendor. Similarly to the Services of ASL RM/A, the investigation was carried out by adopting the method used to perform audits, i.e. by customising the checklist for the assessment of health standards in the production, preparation, administration and sale of foodstuffs of plant origin and drink and the HACCP checklist official controls.

On the whole, 49 inspections were carried out designed for the study of University/IZS. The 24 controlled stores showed the following faults: hygienic-sanitary $(100 \%$ of the controlled stores); traceability/labelling of products (100\%); training of personnel (100\%); prescriptions not acquitted (25\%). In particular, it was found that the plan for self control is formally present in all the stores, but in $90 \%$ of them it is not understood and is disregarded, although the documents have been translated into Chinese. During the inspection activities, 91 proceedings were performed, of which: 33 administrative sanctions, 32 prescriptions, 3 administrative seizures, 6 reports of crime, 4 destructions, 3 seizures and 2 temporary closures. At the end of the activity, anyway, a substantial decrease in serious non-conformities and the permanence of not serious non-conformities was recorded. In addition, a marked improvement of the use of labelling in Italian language on products was found even if accompanied by a poor traceability of the food. Furthermore, the staff and the management 
training on the European legislation on food safety showed no improvement.

\section{Discussion}

The results of these two experiments allow you to make some considerations that can be extended to all kinds of food stores in the area. It has been shown that very few FBOs have a thorough knowledge of the regulations on food safety, especially on food production sanitation. When comparing official control and FBOs, the difficulties one may come across with and have to take into consideration are to face cultural and linguistic differences.

As highlighted, in line with the content of the 2008 report of the Ministry of Health, the diversification of food production, in relation to the different sectors and the size of the FBO, causes a non-uniform awareness of FBO in the way the application of self-control systems is concerned, in order to ensure the product food safety of. In the evaluation of the inspection activities carried out by the competent authorities, in fact, a high prevalence of non-conformities in the framework of general hygiene prerequisites is confirmed, in the application of the HACCP system and in the staff training. Therefore, it is vital to provide a general training program, involving the operators in charge of the control and FBO, in order to allow the effective and definitive resolution of the noncompliances, through the proper use of the audit, an instrument introduced by the regulations of the hygiene package and not yet properly used throughout the national country
(Italian Ministry of Health, 2008).

Indeed, the type of non-conformities detected has highlighted the inadequacy of the role played by the consultants, with regards to the application of the HACCP. In an ethnic community, this makes an expert advice highly desirable, which may interact with FBOs in a better way from a linguistic viewpoint, and, above all, which is to be a real reference point for the different critical aspects for the FBO. The inadequate application of the self-control systems (prerequisites of HACCP) is also reflected in the recurrence of non-conformities in the quality control activity of finished food products. As a matter of fact, it was observed that, the obligation for the FBO to have a self-control plan has been envisaged for 16 years.

\section{Conclusions}

An intervention by the central Authority would be desirable, in order to rule the activities of the self-control consultants, considering the possibility to establish an official list of people in charge of the self-control, who are to be certified and trained, as well as the ability to designate people who are not suitable for that activity. The initiatives to provide the consumer with correct information should be encouraged and could be developed directly at the level of food marketing and service, through periodic campaigns reporting on the major food risks.

\section{References}

Armani A, Castigliego L, Gianfaldoni D, Guidi A, 2011. L'insicurezza alimentare della nuova ristorazione Cinese. Ind Alim 50:711.

European Commission, 2002. Regulation of the European Parliament and of the Council of 28 January 2002 laying down the general principles and requirements of food law, establishing the European Food Safety Authority and laying down procedures in matters of food safety, 178/2002/EC. In: Official Journal, L 31/1, 01/02/2002.

European Commission, 2004. Regulation of the European Parliament and of the Council of 29 April 2004 on official controls performed to ensure the verification of compliance with feed and food law, animal health and animal welfare rules, 882/2004/EC. In: Official Journal, L 191, 28/05/2004.

Guidi A, Armani A, Castigliego L, Li X, Fanzone F, Fusco D, Facibeni E, Gianfaldoni D, 2010. Labeling of ethnic food in the Prato Chinese community. Veterinary Research Communications, vol. Suppl. Vet Res Commun 34(Suppl.1):163-6.

Italian Ministry of Health, 2008. Available from: http://www.salute.gov.it/portale/temi/ p2_6.jsp?lingua=italiano\&id=1225\&area =sicurezzaAlimentare \&menu=igiene

Masotti G, Amadei P, Lanni L, Masotti G, Amadei G, 2010. Pesce crudo: condizioni igieniche, operative e strutturali nei ristoranti giapponesi. Argomenti 2:58-62. 